Supporting Information for:

\title{
Mononuclear Rh(II) PNP-type Complexes. Structure and Reactivity
}

Moran Feller ${ }^{1}$, Eyal Ben-Ari ${ }^{1}$, Gupta Tarkeshwar ${ }^{1}$, Linda J. W. Shimon ${ }^{2}$, Gregory Leitus ${ }^{2}$ Yael Diskin-Posner ${ }^{2}$, Lev Weiner ${ }^{2}$ and David Milstein*,1

${ }^{1}$ Department of Organic Chemistry and ${ }^{2}$ Unit of Chemical Research Support, The Weizmann Institute of Science, Rehovot 76100, Israel 


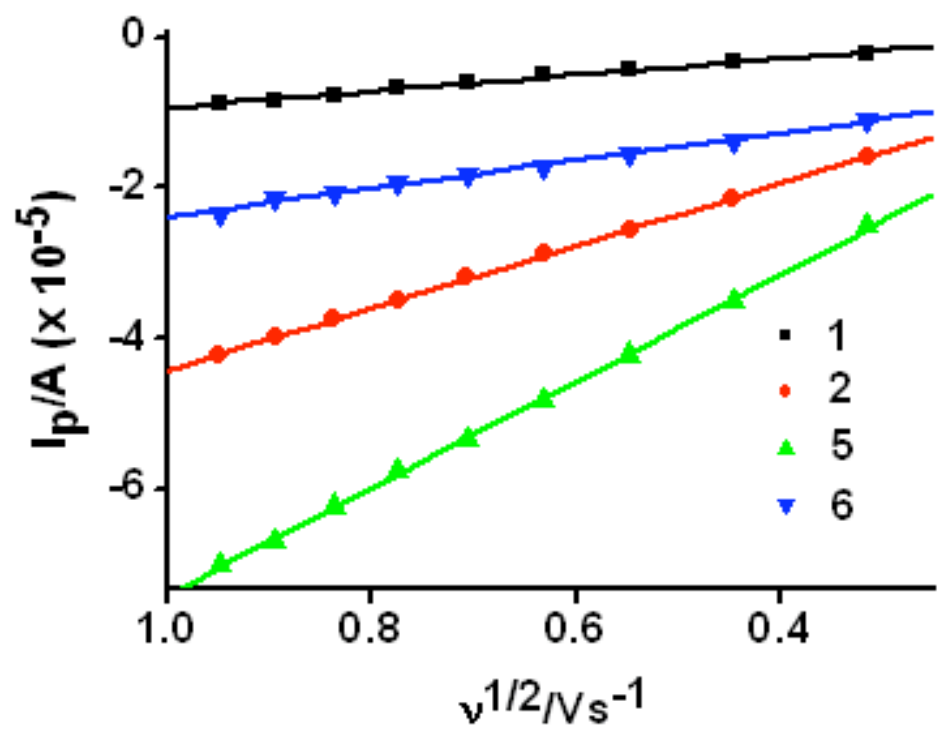

Figure 1. Linear correlation $\left(R^{2}=\sim 0.98\right)$ of the peak current $I_{p}$ versus the square root of scan rate for first reversible redox process of complex $\mathbf{1}, \mathbf{2}$, $5,6$. 